\title{
Bovine oocyte vitrification before or after meiotic arrest: effects on ultrastructure and developmental ability
}

\author{
Carmen Diez ${ }^{\mathrm{a}, *}$, Paloma Duque ${ }^{\mathrm{a}, 1}$, Enrique Gómez ${ }^{\mathrm{a}}$, \\ Carlos O. Hidalgo ${ }^{\mathrm{a}}$, Carolina Tamargo ${ }^{\mathrm{a}}$, Aida Rodríguez ${ }^{\mathrm{a}}$, \\ Lina Fernández ${ }^{\mathrm{b}}$, Santiago de la Varga ${ }^{\mathrm{b}}$, Alba Fernández ${ }^{\mathrm{b}}$, \\ Nieves Facal ${ }^{\mathrm{a}}$, Maite Carbajo ${ }^{\mathrm{b}}$ \\ ${ }^{a}$ Servicio Regional de Investigación y Desarrollo Agroalimentario (SERIDA), \\ Camino de los Claveles 604, Somio, 33203 Gijón, Asturias, Spain \\ ${ }^{\mathrm{b}}$ Facultad de Veterinaria, Campus de Vegazana s/n, 24071 Leon, Spain
}

Received 28 September 2004; received in revised form 19 November 2004; accepted 30 November 2004

\begin{abstract}
The nuclear stage at which oocytes are cryopreserved influences further development ability and cryopreservation affects ultrastructure of both cumulus cells and the oocyte. In this work, we analyze the effects of vitrification at different nuclear and cytoplasmic maturation stages on the oocyte ultrastructure and developmental ability. Culture in TCM199 + PVA with roscovitine $25 \mathrm{M}$ during $24 \mathrm{~h}$ led to meiotic arrest (MA) in cumulus-oocyte complexes (COCs), while permissive in vitro maturation (IVM) was performed in TCM199, 10\% FCS, FSH-LH and 17ß-estradiol for $24 \mathrm{~h}$. Oocytes were vitrified using the open pulled straw method (OPS) with minor modifications. Fresh and vitrified/warmed COCs were fixed as immature, after IVM, after meiotic arrest (MA) and after MA + IVM.

Vitrification combined with MA followed by IVM produced the highest rates of degeneration, regardless of the vitrification time. As a consequence, lower proportions of embryos cleaved in these groups, although differences were eliminated at the five-eight cell stage. Development rates up to day 8 were similar in all experimental groups, being significantly lower than those in fresh controls. Only

* Corresponding author. Tel.: +34 985195300; fax: +34 985195310.

E-mail address: mcdiez@serida.org (C. Diez).

${ }^{1}$ Present address: Centro de Fertilización in vitro de Asturias (CEFIVA), Alvarez Garaya 12, 33206 Gijón, Spain.
\end{abstract}

0093-691X/\$ - see front matter (C) 2004 Elsevier Inc. All rights reserved.

doi:10.1016/j.theriogenology.2004.11.023 
oocytes vitrified after IVM were able to give blastociysts. The morphological alterations observed can be responsible for compromised development. More research is needed to explain the low survival rates of the bovine oocyte after vitrification and warming.

(C) 2004 Elsevier Inc. All rights reserved.

Keywords: Oocyte; Vitrification; Maturation; Meiotic arrest; Blastocysts.

\section{Introduction}

Cryopreservation of oocytes and ovarian tissue has been a long-term goal for researchers. The successful preservation and storage of these female structures has significant importance for the advancement of assisted reproductive technology and medicine. Oocyte and ovary tissue cryopreservation would permit women anticipating loss of gonad function through surgery or other therapies to maintain their reproductive potential, this way circumventing the many ethical and legal questions surrounding human embryo cryostorage [1]. Progress in preservation of these materials would enable better management of livestock and laboratory animal species, and would allow to improve conservation of biodiversity, including endangered species, leading to instant availability of large numbers of oocytes. However, mammalian oocytes remain one of the most difficult cell types to successfully cryopreserve.

Once freed from its follicular environment, the oocyte spontaneously resumes meiosis. This process, involving germinal vesicle breakdown (GVBD), is independent from gonadotropins stimulation [2] and is typically characterized by gradual chromatin condensation and disappearance of a compact nucleolus and nuclear membrane [3]. After meiotic progression and extrusion of the first polar body, the oocyte is arrested at metaphase II and resumes its activity at fertilization. In mammalian oocytes cytoplasm changes known as cytoplasmic maturation take place during maturation, and successful fertilization depends on these changes. Success in cytoplasmic maturation is much more difficult to achieve than nuclear maturation in an in vitro system and inadequate cytoplasmic maturation may seriously compromise the viability of the oocyte. The oocyte recovered from early follicles is usually deprived of influences necessary to complete its development. Inhibition of meiosis is thought to reproduce this period necessary for the oocyte to synthesize and store mRNA and protein. The use of meiotic inhibitors, such as roscovitine, allowed oocytes to improve developmental competence without reducing blastocyist rates [4].

Many approaches have been tried to cryopreserve oocytes with limited success. Classical freezing protocols have been replaced by the most recent vitrification methods, including several modifications, such as vitrification by the open pulled straw method (OPS) [5-9].

After cryopreservation, the oocyte presents compromised developmental competence. This can be primarily explained by nuclear damage [10,11], including spindle disorganization and loss of clumping of microtubules [10,12,13], as well as other ultrastructural alterations seen in vitrified oocytes [14]. The nuclear stage at which oocytes are submitted to cryopreservation influences further ability of the oocyte to develop after in 
vitro fertilization (IVF) [15]. Conditions during in vitro maturation (IVM) largely modify the maturation outcome, and can influence the sensitivity of the oocyte to cryopreservation [16].

A limited number of studies have focused on effects of low temperatures on the oocyte ultrastructure, and little is known about ultrastructural modifications of bovine oocytes following meiotic inhibition in vitro. Thus, Faerge et al. [17] described modifications in the nucleus of fresh bovine oocytes after meiotic inhibition with various chemical and biological inhibitors, and Lonergan et al. [18] showed that inhibition of meiosis induced wide ultrastructural changes. Interestingly, these alterations coexist with embryonic development rates comparable to those of normal in vitro matured oocytes [19-22]. To date, no studies on ultrastructure of the cryopreserved cumulus-oocyte complexes (COCs) submitted to meiotic inhibition followed by IVM have been developed. Therefore, the purposes of this work were: (1) to study the ability of the bovine oocyte to survive vitrification at different stages of maturation and meiotic arrest; and (2) to study the ultrastructure of warmed COCs vitrified at different stages of maturation and meiotic arrest.

\section{Materials and methods}

All chemicals were purchased from Sigma (Madrid, Spain), unless otherwise indicated.

\subsection{Collection of COCs}

Ovaries recovered from slaughtered cows were placed in $\mathrm{NaCl}$ solution $(9 \mathrm{mg} / \mathrm{mL})$ containing antibiotics (penicillin, $100 \mathrm{UI} / \mathrm{mL}$ and streptomycin sulphate, $100 \mu \mathrm{g} / \mathrm{mL}$ ) and maintained at $25-30{ }^{\circ} \mathrm{C}$ until COCs collection. The ovaries were washed twice in distilled water and once in freshly prepared saline. Visible follicles $2-7 \mathrm{~mm}$ in size were aspirated through an 18 gauge needle connected to a syringe, and the contents recovered in a $50 \mathrm{~mL}$ Corning tube. Follicular fluid and COCs were placed in an ovum concentrating filter (Comextrade, Tarragona, Spain) and rinsed three times with holding medium (HM: TCM199-Invitrogen, Barcelona, Spain, $25 \mathrm{mM}$ Hepes and BSA $0.4 \mathrm{mg} / \mathrm{mL}$ ).

Oocytes enclosed in a compact cumulus with evenly granulated cytoplasm were selected and washed three times in HM. Those COCs assigned to groups undergoing meiotic inhibition were washed twice in basic medium (BM: TCM199 + PVA $0.5 \mathrm{mg} / \mathrm{mL}$ ) containing roscovitine $25 \mu \mathrm{M}$, which was previously dissolved in DMSO and stored in aliquots at $-20{ }^{\circ} \mathrm{C}$ until use, as described by Mermillod and co-workers [4]. Meiotic arrest was accomplished by culturing COCs in BM with roscovitine $25 \mu \mathrm{M}$ during $24 \mathrm{~h}$. Those COCs cultured under permissive, non-meiotically inhibited maturation conditions were washed three times in HM and twice in maturation medium (MM). In vitro maturation was carried out in MM containing $10 \%$ fetal calf serum (FCS), pFSH ( $1 \mu \mathrm{g} / \mathrm{mL}), \mathrm{LH}(5 \mu \mathrm{g} /$ $\mathrm{mL})$ and $17 \beta$-estradiol $(1 \mu \mathrm{g} / \mathrm{mL})$ for $22 \mathrm{~h}$. The COCs submitted to meiotic arrest were allowed to mature for $24 \mathrm{~h}$ under permissive conditions. Incubations were performed in four-well dishes (Nunc, Biocen, Spain) containing $500 \mu \mathrm{L}$ of culture medium at $39{ }^{\circ} \mathrm{C}$ in $5 \% \mathrm{CO}_{2}$ under air and high humidity. 


\subsection{Vitrification and warming}

Vitrification and warming of COCs followed the OPS method described by Vajta et al. [5] with minor modifications. Briefly, oocytes were partially denuded by gentle vortexing until only two-three layers of cumulus cells (CC) remained on the surface. Oocytes were handled in a basic vitrification medium (BV), consisting of TCM 199-Hepes $+20 \%$ FCS All procedures were performed in a warm room $\left(30{ }^{\circ} \mathrm{C}\right)$ on a heated surface $\left(41^{\circ} \mathrm{C}\right)$. Groups of four-five oocytes were exposed to BV with $10 \% \mathrm{EG}+10 \% \mathrm{DMSO}$ (vitrification solution-1; VS1) for $30 \mathrm{~s}$ and then moved into a well containing BV with $20 \% \mathrm{EG}+20 \%$ $\mathrm{DMSO}+0.5 \mathrm{M}$ sucrose (vitrification solution-2; VS2). After a quick passage of oocytes in VS2, a drop of $6 \mu \mathrm{LVS} 2$ containing the oocytes was made. Oocytes were loaded into OPS straws (sOPS; Comextrade, Tarragona, Spain) in an approximately $1 \mathrm{~mm}$ higher cylinder of VS2 containing the oocytes, formed by capillary action by touching the narrow end of the straw with the droplet. Then, the straws were plunged in liquid nitrogen (LN). The time spent by the oocytes in VS2 (including loading) was 20-25 s.

Warming was conducted by immersing the pulled end of the straw directly in $1.2 \mathrm{~mL}$ of $0.25 \mathrm{M}$ sucrose in BV. They were kept for $5 \mathrm{~min}$, and then transferred into a $0.15 \mathrm{M}$ sucrose medium in BV for another $5 \mathrm{~min}$, and subsequently transferred and washed twice in BV. After warming, when necessary depending on the treatment, COCs were cultured to accomplish the final maturation step before being submitted to IVF and culture $(2 \mathrm{~h}$ for oocytes matured prior to vitrification).

\subsection{In vitro fertilization}

Sperm separation was carried out using a swim-up procedure similar to that reported by Parrish et al. [23]. Briefly, semen from frozen straws of a single bull of proven fertility were thawed in a water bath and added to a polystyrene tube containing $1 \mathrm{~mL}$ of pre-equilibrated Sperm-Tyrode-Albumin-Lactate-Pyruvate (Sperm-TALP). After $1 \mathrm{~h}$ of incubation, approximately $700 \mu \mathrm{L}$ of the upper layer of supernatant containing the motile sperm was removed. The sperm were centrifuged for $7 \mathrm{~min}$ at $100 \times g$ and the supernatant aspirated to leave a pellet of approximately $100 \mu \mathrm{L}$ in volume. Sperm concentration was determined with a haemocytometer.

The COCs belonging to the different experimental groups were washed twice in HM, twice in pre-equilibrated fertilization medium (Fert-TALP), and placed in four-well culture dishes containing $500 \mu \mathrm{L}$ of Fert-TALP with heparin $(10 \mu \mathrm{g} / \mathrm{mL}$, Calbiochem, La Jolla, CA). Spermatozoa were then added at a concentration of $2 \times 10^{6}$ cells $/ \mathrm{mL}$. In vitro fertilization was accomplished by incubating oocytes and sperm cells together for 18-20 h at $39{ }^{\circ} \mathrm{C}$ in $5 \% \mathrm{CO}_{2}$ under high humidity.

\subsection{Embryo culture}

Presumptive zygotes were slightly passed through a small gauge pipette to eliminate cumulus cells and sperm, washed three times in HM and twice in culture medium.

Before culture, morphological appearance of the ova was evaluated under a stereomicroscope. Only presumptive zygotes with normal morphology were cultured. 
Zygotes with ruptured zona pellucida, loss of cytoplasmic contents or other degenerative signs were counted and discarded. Embryo culture was performed in modified synthetic oviduct fluid (SOF) containing amino-acids, citrate and myo-inositol [24] adjusted to 285 mOsm and $\mathrm{pH} 7.2-7.3$. The FCS $(5 \%)$ was added at $42 \mathrm{~h}$ post-fertilization (post-FIV). Droplets of culture medium (1-2 $\mu \mathrm{L} / \mathrm{embryo})$ were prepared in four-well dishes under mineral oil and equilibrated for $2 \mathrm{~h}$ before addition of zygotes. Incubations were carried out at $39{ }^{\circ} \mathrm{C}, 5 \% \mathrm{CO}_{2}, 5 \% \mathrm{O}_{2}$ and $90 \% \mathrm{~N}_{2}$. Culture media were renewed at $66 \mathrm{~h}$ (day 3) and $138 \mathrm{~h}$ (day 6) post-FIV, and embryonic development was recorded on days 3, 6, 7 and 8.

\subsection{Experimental design}

Treatments are described in Table 1, and groups are termed using letter "v" (vitrification) to indicate timing for the vitrification step.

In groups vM and vAM, the oocytes were vitrified as immature; after warming, one part of the oocytes was in vitro matured (vM), and the rest were submitted to meiotic arrest followed by IVM (vAM). Oocytes belonging to the Mv group were vitrified after $22 \mathrm{~h}$ of IVM and matured for 2 supplementary hours after warming. Oocytes from AvM group were vitrified after meiotic arrest, and matured for $24 \mathrm{~h}$ after warming. Oocytes in the group $\mathrm{AMv}$ were meiotically arrested, matured for $22 \mathrm{~h}$, and subsequently vitrified and matured for $2 \mathrm{~h}$ after warming.

Two groups of oocytes acted as controls. In the group $\mathrm{M}$, fresh oocytes were in vitro matured, fertilized and cultured without any treatment; in the group AM, fresh oocytes were in vitro meiotically arrested and matured, fertilized and cultured.

\subsection{Electron microscopy}

Fresh and vitrified/warmed oocytes corresponding to one of each stage of the experimental design were fixed for ultrastructural analysis (see Table 2). Briefly, the COCs were fixed in $2.5 \%$ glutaraldehyde in $0.1 \mathrm{M}$ phosphate buffer ( $\mathrm{pH}$ 7.4-7.6) and postfixed in $1 \%$ osmium tetroxide prior to dehydration in graded ethanol and embedding in Epon 812 resin. Ultrathin and $1 \mu \mathrm{m}$-thick semithin sections were cut with ultramicrotome (LKB Bromma 2088, LKB, Switzerland). Semithin sections were stained with $1 \%$ toluidine blue for selection of fields. Ultrathin sections were stained with uranyl acetate and lead citrate

Table 1

Treatments of COCs before vitrification and after warming

\begin{tabular}{llc}
\hline In vitro treatments & & \\
\hline Before vitrificacion & After warming & Group \\
\hline Untreated, immature & Maturation (M) & vM \\
Untreated, immature & Meiotic arrest (MA) + maturation & vAM \\
Meiotic arrest & Maturation & AvM \\
Meiotic arrest + maturation & 2 h prolonged maturation & AMv \\
Maturation & 2 h prolonged maturation & Mv \\
Control fresh, non-vitrified, matured & & M \\
Control fresh, meiotically arrested and matured & & AM \\
\hline
\end{tabular}


Table 2

Morphology (electron microscopy) of oocytes fresh or vitrified at different maturation steps

\begin{tabular}{|c|c|c|c|c|c|c|c|c|c|}
\hline \multirow[t]{2}{*}{ Maturation status analyzed } & \multicolumn{3}{|l|}{ Treatments } & \multirow[t]{2}{*}{$N$} & \multicolumn{2}{|c|}{ Cumulus cells } & \multicolumn{2}{|c|}{ Main oocyte cytoplasmic organelle deviations } & \multirow[t]{2}{*}{$\mathrm{GJ}^{\mathrm{c}}$} \\
\hline & Step 1 & $\mathrm{~V} / \mathrm{W}$ & Step 2 & & Viable $^{\mathrm{a}}$ & Expansion $^{\mathrm{b}}$ & Mitochondria & CG & \\
\hline Immature & No & No & No & 10 & $>95$ & 0 & None & None & $>90$ \\
\hline Immature & No & Yes & No & 12 & $>50$ & 0 & None & Partial migration & $>60$ \\
\hline Matured & IVM & No & No & 9 & $>95$ & +++ & None & None & $>90$ \\
\hline Matured & IVM & Yes & No & 11 & $>60$ & +++ & $>40 \%$ degenerated & Reduced number & $>90$ \\
\hline Matured & No & Yes & IVM & 12 & $>50$ & +++ & None & Reduced number & $>60$ \\
\hline Meiotically arrested & MA & No & No & 10 & $>60$ & 0 & $>50 \%$ degenerated & No migration & $>60$ \\
\hline Meiotically arrested & No & Yes & MA & 9 & $>40$ & 0 & $>90 \%$ degenerated & Degeneration & $>30$ \\
\hline Matured after MA & MA + IVM & No & No & 11 & $>60$ & +++ & None & Reduced number & $>60$ \\
\hline Matured after MA & $\mathrm{MA}+\mathrm{IVM}$ & Yes & No & 10 & $>60$ & ++ & Degenerated & Disappeared & 0 \\
\hline Matured after MA & MA & Yes & IVM & 9 & $<20$ & 0 & Degenerated & Degeneration & 0 \\
\hline Matured after MA & No & Yes & $\mathrm{MA}+\mathrm{IVM}$ & 12 & $<20$ & ++ & Degenerated & Degeneration & 0 \\
\hline
\end{tabular}

Treatments: culture before (step 1) or after (step 2) vitrification and warming (V/W); MA: meiotic arrest; IVM: in vitro maturation; CG: cortical granules; replicates: 3 ; $N$ : total number of oocytes analyzed.

a Cumulus cells viability: rate of viable cumulus cells.

${ }^{\mathrm{b}}$ Cumulus cells expansion:,$+++>90 \%$ of oocytes with all cumulus cells layers expanded;,$++>50 \%$ of oocytes with all cumulus cells layers expanded;,$+<50 \%$ of oocytes with cells of corona radiate expanded; $0,>90 \%$ oocytes with cumulus cells unexpanded.

${ }^{\mathrm{c}}$ Gap junctions status: rate of GJ with normal appearance. 
and were observed with a JEOL JEM 1010 transmission electron microscope (JEOL, Japan) under $60 \mathrm{kV}$.

We analyzed expansion degree in $\mathrm{CC}$, ultrastructure of both $\mathrm{CC}$ and the oocyte focusing on organelle status, gap junctions (GJ) between $\mathrm{CC}$ and the oocyte, integrity of the plasmatic membrane and mitochondria, location of CG, endoplasmic reticulum, and lipid droplets as well as cytoplasmic vesicles.

\subsection{Statistical analysis}

Data from embryo development were analyzed in two steps. Firstly, since these values can be represented by contingency tables, those factors significantly affecting the variables were identified by means of the procedure categorical data modeling (CATMOD) using the SAS model [25]. CATMOD extends analysis from continuous data to categorical data, fitting linear models to functions of response frequencies. Treatment and replicate were found to have significant influence on dependent variables. Secondly, those factors identified to be significant were used to fit a linear model using the procedure general linear models (GLM; SAS) [25]. This procedure performs analysis of variance for unbalanced data. GLM was used to estimate least square means (LSM) for each fixed effect having a significant $F$-value. Duncan's multiple-range test was carried out on raw means calculated for the main effects, and data are referred to frequency percentages of oocytes.

\section{Results}

Morphological appearance of COCs immediately after warming was normal in all groups; consequently, all recovered oocytes after warming were submitted to IVF. Zygotes derived from vitrified/warmed oocytes appeared as much more fragile structures than fresh controls, and removal of CC after fertilization was usually associated with damaged both $\mathrm{ZP}$ and oolema, together with loss of cytoplasmic contents (Table 3).

Vitrification combined with meiotic inhibition followed by IVM produced the highest rates of oocytes showing degenerated appearance after IVF, regardless of the vitrification time. Thus, percentages of $49.9 \pm 5.9$ within oocytes vitrified as immature (group vAM)

Table 3

Degeneration rates at day 1 and embryo development up to day 8 of oocytes vitrified at different times of culture

\begin{tabular}{llllllll}
\hline Group & $N$ & $R$ & Day 1 & Day 3 & Day 6 & Day 8 & \\
\cline { 3 - 7 } & & & Degenerated $(\%)$ & Cleaved $(\%)$ & Morulae $(\%)$ & Blastocysts $(\%)$ & Expansion $(\%)$ \\
\hline vM & 139 & 6 & $17.6 \pm 5.9 \mathrm{a}$ & $25.0 \pm 4.6 \mathrm{ab}$ & $2.8 \pm 4.2 \mathrm{a}$ & $0.0 \mathrm{a}$ & $0.0 \mathrm{a}$ \\
vAM & 107 & 7 & $49.9 \pm 5.9 \mathrm{~b}$ & $10.5 \pm 4.6 \mathrm{a}$ & $0.5 \pm 4.2 \mathrm{a}$ & $0.0 \mathrm{a}$ & $0.0 \mathrm{a}$ \\
$\mathrm{Mv}$ & 142 & 7 & $22.9 \pm 6.8 \mathrm{a}$ & $32.8 \pm 4.2 \mathrm{~b}$ & $5.2 \pm 3.8 \mathrm{a}$ & $1.6 \pm 3.2 \mathrm{a}$ & $1.2 \pm 2.3 \mathrm{a}$ \\
AvM & 126 & 6 & $27.6 \pm 5.9 \mathrm{a}$ & $31.6 \pm 4.6 \mathrm{~b}$ & $4.3 \pm 4.2 \mathrm{a}$ & $0.0 \mathrm{a}$ & $0.0 \mathrm{a}$ \\
AMv & 132 & 7 & $37.3 \pm 5.9 \mathrm{ac}$ & $26.3 \pm 4.2 \mathrm{ab}$ & $0.8 \pm 3.8 \mathrm{a}$ & $0.0 \mathrm{a}$ & $0.0 \mathrm{a}$ \\
M & 238 & 7 & & $90.7 \pm 4.2 \mathrm{c}$ & $51.5 \pm 3.8 \mathrm{~b}$ & $36.4 \pm 3.2 \mathrm{~b}$ & $27.8 \pm 2.3 \mathrm{bx}$ \\
AM & 156 & 7 & & $83.0 \pm 4.2 \mathrm{c}$ & $47.5 \pm 3.8 \mathrm{~b}$ & $29.3 \pm 2.4 \mathrm{~b}$ & $16.9 \pm 2.3 \mathrm{by}$ \\
\hline
\end{tabular}

$N$ : number of oocytes recovered after warming; $R$ : replicates; values are LSM \pm S.E.; different letters differ significantly (a, b, c: $p<0.01 ; \mathrm{x}, \mathrm{y}: p<0.05)$. Development data refer to cultured oocytes. 
and $37.3 \pm 5.9$ of oocytes treated prior to vitrification (group AMv), showed signs of degeneration. As a consequence, lower proportions of embryos cleaved in these groups, although differences were eliminated at the 5-8 cell stage (data not shown).

Zygotes derived from fresh oocytes (groups M and AM) developed up to day 8 at higher rates $(p<0.01)$ than those derived from the remaining experimental groups. Only oocytes vitrified after permissive maturation (group Mv) were able to give blastocysts. On the other hand, freshly matured, non-inhibited oocytes (group M) expanded at higher rates than their counterparts undergoing meiotic arrest (group AM).

\subsection{Ultrastructural study}

The main morphological observations are summarized in Table 2, based on descriptions of Lonergan et al. [18].

When processed as fresh and immature, COCs were characterized by several layers of non-expanded CC with normal nuclei; $\mathrm{CC}$ foot endings extended through the $\mathrm{ZP}$ and formed communications with the oocyte by means of GJ. Mitochondria were located in the periphery of the oocyte with well marked electron-lucent crestae. Lipid droplets were observed in close proximity to the mitochondria, together with the endoplasmic reticulum. Clusters of $\mathrm{CG}$ appeared on the cortex of the ooplasm. Electron-lucent vesicles were distributed all over the oocyte.

After vitrification and warming, immature oocytes showed 30-50\% lysis within the CC, with necrosis in the nuclei and lysis of the cellular membrane. These cells exhibited swollen mitochondrial crestae and endoplasmic reticulum. The cytoplasmic ultrastructure of the oocyte did not appear altered. However, reduced numbers of both microvilli extending from the $\mathrm{CC}$ to the oocyte and GJ were observed. The location of CG was slightly irregular.

After IVM of immature vitrified and warmed oocytes (group vM), CC expanded correctly and showed morphologically normal nuclei and organelles (Fig. 1). The integrity of the cellular membrane was conserved. The CG were slightly reduced in number, and lined up along the oolema. Structures communicating CC and the oocyte were maintained. At the cytoplasmic level, the oocyte showed no structural alterations.

Oocytes vitrified as immature, once warmed and submitted to meiotic inhibition, showed lysis and signs of apoptosis in the surrounding CC (Fig. 2). When these oocytes were submitted to IVM (group vAM) lysis spread over the oocyte and CC (Fig. 3) which was not compatible with further development.

The microscopic analysis of control fresh IVM oocytes (group M) allowed the observation of layers of expanded CC and GJ entering the ZP and the periviteline space towards the ooplasm. Morphological appearance of the oocyte cytoplasm was normal, with mitochondria showing electron-lucent crestae. A big population of vesicles was observed located near to mitochondria. Mitochondria, endoplasmic reticulum and lipid droplets appeared, often in close association. The CG were uniformly distributed in an alignment close to the plasmatic membrane.

When IVM oocytes were vitrified/warmed (group Mv), no effect was observed on CC, which kept expansion degree comparable to fresh oocytes, and intact GJ. However, location of CG was slightly different to fresh controls, with cluster located in the cortex or 


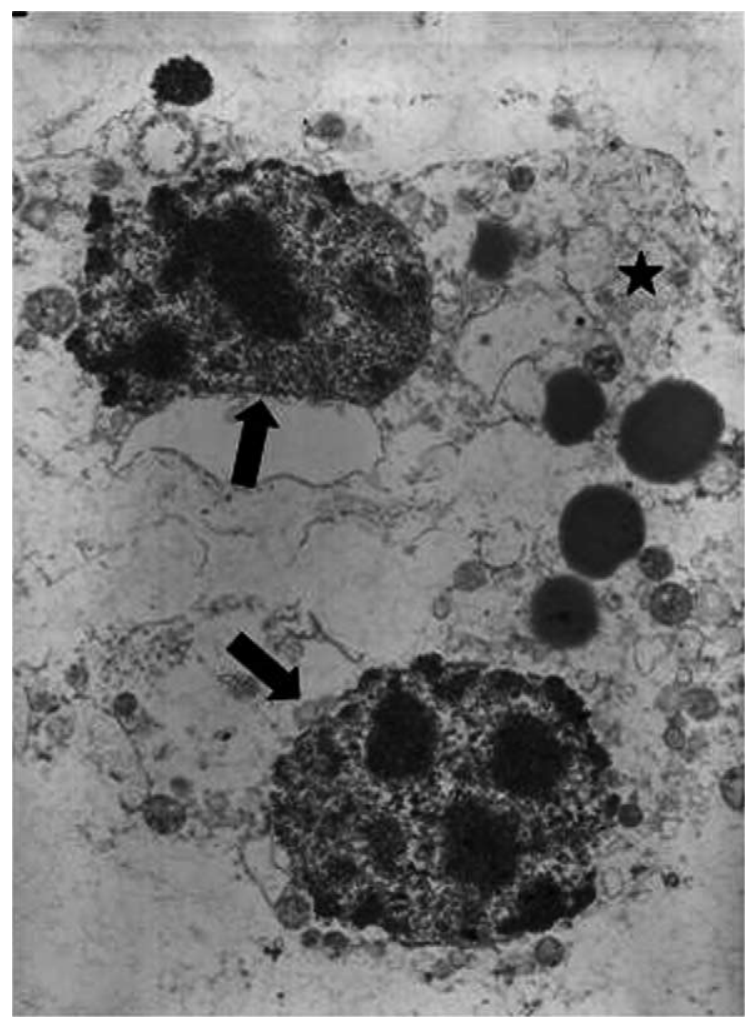

Fig. 1. Cumulus cells from a COC vitrified as immature and matured after warming (group vM). Nuclei (arrows) and cytoplasm (star) appear with a normal structure $(5000 \times)$.

not well aligned along the oolema. The periviteline space was reduced. The crestae of the mitochondria were electron-dense, as a sign of morphological alteration in the organelle.

Fresh COCs submitted to meiotic inhibition showed no expansion and signs of nuclear necrosis in CC. The plasmatic membrane of the oocyte was slightly irregular and the perivitelline space was larger than in immature, fresh oocytes. However, distribution of mitochondria, cytoplasmic vesicles and lipid droplets were similar to those observed in immature oocytes. Some mitochondria appeared as swollen and pale. Clusters of CG were observed both in the deep cortex and in the periphery of the oocyte.

Oocytes that were vitrified after meiotic inhibition and before maturation (group AvM) resulted in electron-dense crestae within mitochondria and degenerative signs in the ooplasm. In contrast, when meiotically arrested and matured oocytes were studied fresh (group AM), CC showed expansion and contained normally appearing organelles, with GJ unaltered, then linking $\mathrm{CC}$ and the oocyte. In these oocytes, mitochondria, vesicles, reticulum endoplasmic and lipid droplets presented the same appearance as fresh oocytes matured without meiotic inhibition. However, inducing meiotic arrest led to irregular plasmatic membrane and increased perivitelline space. The number of CG was slightly reduced. 


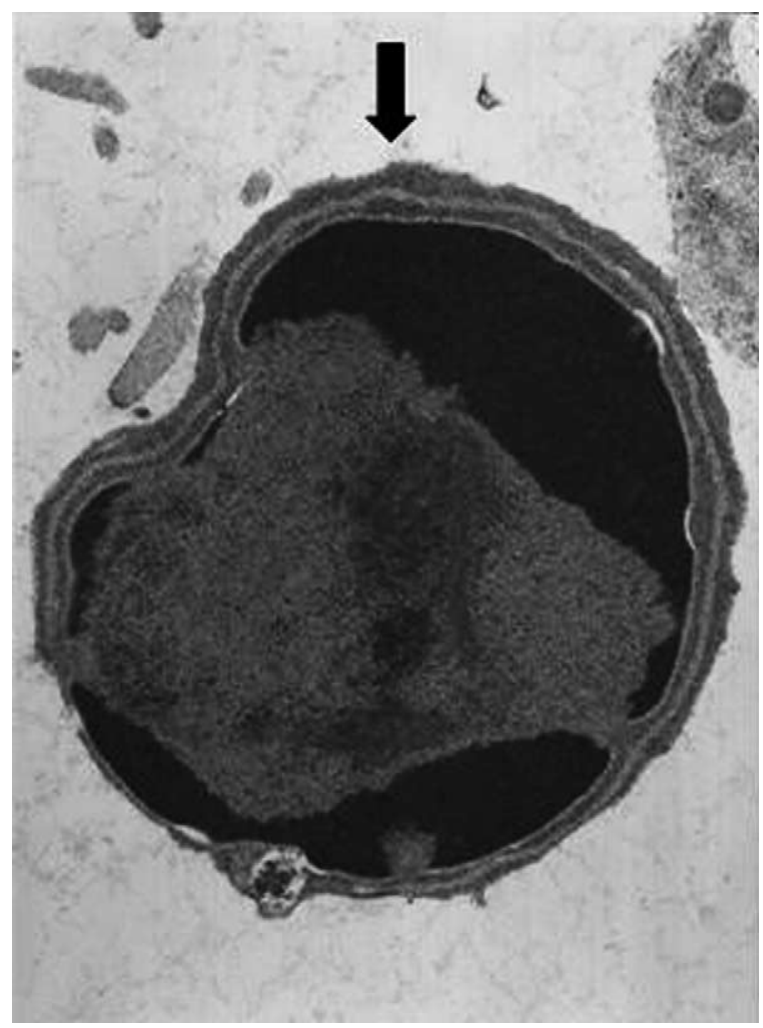

Fig. 2. Apoptosis in a nucleus (arrow) of a cumulus cell from a COC vitrified as immature and submitted to a meiotic inhibition followed by IVM after warming $(10,000 \times)$.

Vitrification and warming of oocytes after meiotic arrest and maturation (group AMv) was responsible for lysis of $50 \%$ of the CC, losses of integrity in GJ and degeneration of mitochondria of both $\mathrm{CC}$ and oocyte. Interestingly, CG could not be observed in these oocytes. These morphological alterations seemed to be not compatible with development after IVF and IVC.

\section{Discussion}

In this work, we analyzed the ultrastructure of bovine COC and the ability of the enclosed oocyte to survive vitrification at different stages of nuclear and cytoplasmic maturation. In vitrified oocytes degeneration was higher after meiotic arrest following IVM, and independent on the timing of the vitrification step. Cleavage rates from group vAM were lower than in the other groups. However, development rates from day 3 to day 8 were similar in all vitrified groups, although lower than in fresh controls. We obtained blastocysts only from oocytes vitrified after IVM. 


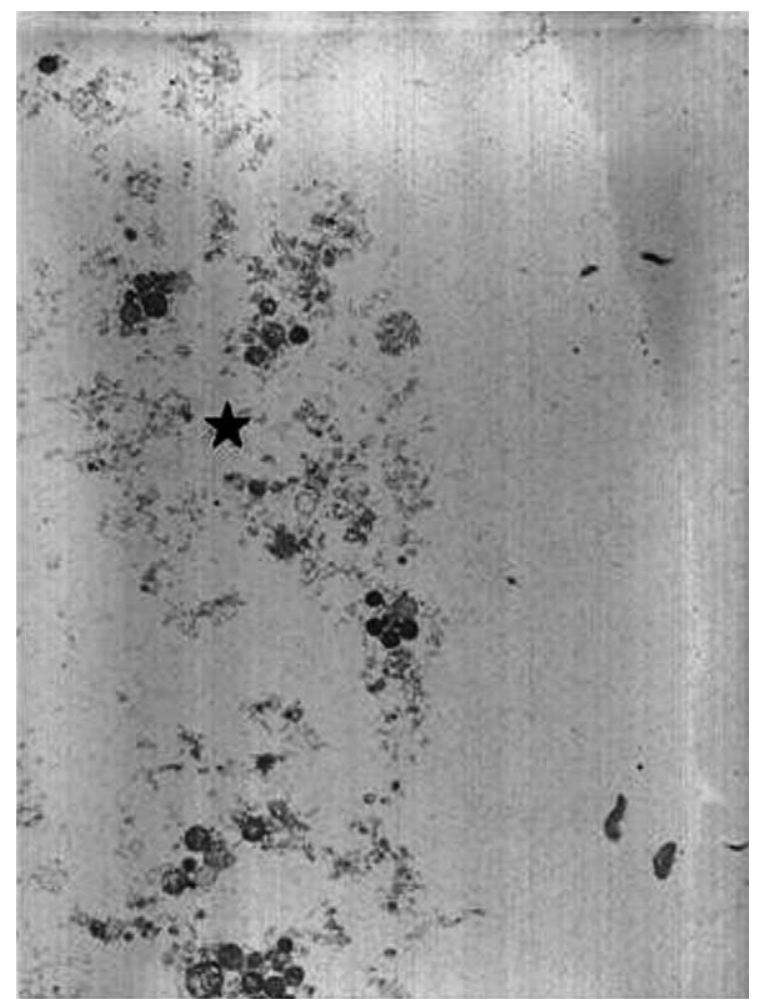

Fig. 3. Lysis of the cytoplasm (star) of an oocyte vitrified as immature and submitted to meiotic arrest after warming $(3000 \times)$.

The chilling sensitivity of the mammalian oocyte is well documented [1,26,27], and consequently success to survive cryopreservation is limited. Cryopreservation involves controlling many variables, such as cryoprotectant $(\mathrm{CP})$ type used, the method for adding and removing CPs, and cooling and thawing rates, each of these factors being a possible source of cell damage. The development of successful methods for cryopreservation requires understanding these effects and how they interact.

Aneuploidy and polyploidy in the oocyte itself or in cumulus cells resulting from a cooled or cryopreserved, cleaving oocyte have been claimed to be one of the leading causes of compromised developmental competence [28]. These abnormalities are normally associated with the temperature-sensitive nature of microtubules. Metaphase II (MII) spindles, formed mainly from microtubules, undergo disassembly and reassembly during the processes of cooling and re-warming. Unfortunately, in some species, such as bovine and human, MII spindles cannot completely reform after warming due to pericentriolar materials lack in some oocytes [29]. Partially formed spindles will bring about chromosome missarrangement/displacement in some oocytes and result in aneuploidy. The abnormality in spindle reformation may also result in retention of the second polar body in the oocytes at the time of fertilization, which in turn will give rise to polyploid zygotes and embryos [30]. In bovine, meiotic spindles of cooled $\left(4\right.$ and $\left.25^{\circ} \mathrm{C}\right)$ oocytes were reduced or 
completely absent, and a chromosomal dispersion directly related to the time of exposure to cooling temperatures was observed [31]. Moreover, re-warming these oocytes did not restore normal spindle morphology. Men et al. [16] detected DNA fragmentation without alteration of the oocyte morphology as a direct consequence of cryopreservation, being unknown the mechanisms underlying this damage. The osmotic stress during dehydration and rehydration may also account for cryodamage [32]. To overcome extreme sensitivity to chilling temperatures, vitrification replaced classical freezing which results in increased morphological damage to oocytes at any maturation stage [33] and reduced embryonic development compared to vitrified oocytes [34].

In the present work, we have found that the maturation stage at vitrification affected degeneration after IVF and subsequent cleavage rates. Moreover, although development rates from day 3 to day 8 were similar among all the vitrified groups, we obtained blastocysts only after vitrification/warming of matured oocytes (group Mv). It has to be taken into account that in our work vitrified oocytes showed at warming an appearance similar to their fresh counterparts, so we decided to fertilize all recovered COCs. Signs of degeneration (fragmented cytoplasms, ruptured ZP and loss of cytoplasmic contents) were often observed at the onset of culture in zygotes derived from vitrified oocytes with regards to zygotes derived from fresh oocytes. Among vitrified COCs, we obtained blastocysts only from oocytes undergoing IVM. As judged by the rates of degenerated oocytes on day 1 in our work, both immature (group vM) and matured (group Mv) survived vitrification better than the other groups. Degeneration percentages are lower and cleavage rates are higher that those obtained by other authors [15,32,35], although development up to the morula and blastocyst stage is compromised. Such as observed in our work, a low correlation between cleavage and further embryonic development has been previously stated [9,36]. Nevertheless, cleavage rates higher than $45 \%$ for oocytes vitrified both as immature and matured have been reported by other researchers $[9,16]$. In our work, blastocyst rates produced from vitrified, mature oocytes are lower than those presented in previous reports $[5,9,10,15,16,35]$ and comparable to those published by Men et al. [16] using immature oocytes. Live calves have been obtained from vitrified/ warmed immature oocytes [9].

The oocyte survival to vitrification did not improve when oocytes were cultured through meiotic inhibition and maturation, irrespective of the timing of the vitrification step. Interestingly, the highest rates of morphological degeneration after IVF corresponded to groups in which oocytes were meiotically arrested. As a consequence, these groups presented the lowest cleavage rates, although day 8 development rates were similar in all groups of vitrified oocytes. Fresh meiotically inhibited oocytes reached morulae rates comparable to fresh, not inhibited, IVM oocytes, although expansion within CC was slightly reduced. This fact can be explained as oocytes submitted to a meiotic arrest could need a shorter period to accomplish nuclear maturation [37]. However, we decided to use a $24 \mathrm{~h}$ period of IVM in order to get comparable results to previous work [19-22].

Men et al. [16] demonstrated that MII stage oocytes survive cryopreservation better than GVBD oocytes, being cytoskeleton in the first meiotic division particularly susceptible to damage. MII oocytes display a more flexible cytoskeleton, probably less sensitive to cryodamage [38]. Although oocytes at the GVBD stage were reported to be more resistant to cooling than GV and MII oocytes, when cryopreservation is attempted, GVBD oocytes 
showed themselves to be more sensitive to low temperature than MII oocytes [16]. Oocytes matured for 0,6 and $12 \mathrm{~h}$ had less ability to survive cryopreservation than $24 \mathrm{~h}$ IVM oocytes [15]. In bovine oocytes, active transcription and translation mostly occurs at GVBD and to a lesser extent at later stages of meiotic maturation [11,39-42].

Studies on chilling sensitivity conducted on MII stage oocytes found that the main damage occurred due to meiotic spindle disorganization followed by microtubule depolymerization $[11,26,43,44]$. Cryopreservation of immature oocytes could provide a partial solution for damage inflicted to cytoskeleton by vitrification, as oocytes do not contain polymerized tubules at this stage. However, oocytes at the GV stage are extremely sensitive to chilling temperatures, with the damage occurring at the cytoplasmic membrane level [33].

Coupling somatic granulosa cells with the GV-stage oocyte is vital for oocyte maturation and subsequent embryo development to occur [45,46]. Removal of several layers of CC by pipetting COCs has been described by Vajta et al. [5] as a previous step in the vitrification procedure. In our work, the COCs were submitted to a gentle vortexing for eliminating those layers of cumulus cells. This fact could be responsible for the greater sensitivity we found in vitrified/warmed oocytes and the lower developmental rates obtained after IVF, compared with the data reported by those authors [5,9]. The threedimensional COC is likely to be particularly prone to physical disruption caused by ice crystal formation [47]. Even if ice crystal formation is circumvented during vitrification, the broad difference in size between the oocyte and its associated CC yields distinct responses to stress during cryopreservation.

Exposure to cryoprotectants contained in a vitrification solution affects mitochondria, vesicles, and/or microvilli and reduces embryonic development of MII oocytes, probably as a consequence of osmotic shock [35]. Losses of microvilli indicate that the close coupling between the oocyte and its CC investment has been disrupted [48]. Since decoupling of $\mathrm{CC}$ occurs gradually during normal meiotic maturation, it is likely that premature breakdown eliminates the metabolic communication essential to maturation. Hurtt et al. [49] obtained $60 \%$ of MII after vitrification of bovine immature oocytes by OPS method and they observed damage to the cumulus-oocyte junctions. In the mature oocyte, however, close coupling is no longer essential, and the oocyte may be less vulnerable to functional damage by exposure to cryoprotectant or cryopreservation. Therefore, immature oocytes seem to be more vulnerable to cryodamage than matured oocytes [36], which contributes to explain our results. As previously demonstrated in mouse [29], exposure to high $\mathrm{CP}$ concentrations may trigger premature release of $\mathrm{CG}$, altering their distribution after warming and IVM [49] and resulting in hardening of the ZP with decreased fertilization outcomes [50,51].

We could observe that vitrification of immature oocytes produced lysis in the $\mathrm{CC}$ and significant damage in GJ integrity, disrupting communication between $\mathrm{CC}$ and oocyte. These alterations are consistent with previous findings [11,36]. Interestingly, the cytoplasmic structure of the vitrified oocyte was not altered, as evidenced by location and morphology of cellular membrane, organelle, CG, lipid droplets, mitochondria and cytoplasmic vesicles, resembling structures in fresh oocytes. The lower number of GJ together with a putative defective coupling between $\mathrm{CC}$ and the oocyte may explain the low development rates seen in these oocytes. Unlike immature, COCs vitrified once matured 
did not show the above reported alterations, either in $\mathrm{CC}$ or in the GJ, similar to fresh oocytes. Moreover, the integrity of the cellular membrane was preserved and the expansion of the CC resembled that of freshly matured oocytes.

Apoptosis [10,26,36,52] and disorganization of the MII spindle as a cause of chromosomal aberrations $[31,52,53]$, have been observed in oocytes after vitrification procedures. In addition, ZP may be either broken or at least modified by the premature release of CG, as seen in frozen-thawed human and mouse oocytes [44,54]. Chilling can induce irreversible phase changes of lipid bilayers and even membrane lysis in bovine oocyte membranes $[33,55]$. Modifications to the structure of cytoskeleton, mitochondria, CG and nucleoli [53] and smooth endoplasmic reticulum [15] have also been observed in vitrified-warmed bovine oocytes.

From our results, we can infer that alterations due to vitrification in the oocyte after IVM are partially reversible and allow reaching the blastocyst stage. Modification of the culture systems are worth to be tested in order to overcome the cryodamage inflicted to the oocyte [10].

Meiotic inhibition in vitro has been described to induce ultrastructural modifications in the bovine oocyte $[11,17,18]$. In the present work, meiotic arrest prior to IVM of fresh oocytes did not alter the structure of CC, which showed expansion and absence of morphological changes in organelles. However, meiotic arrest after vitrification and warming of immature oocytes led to moderate lysis in the inhibited oocyte and signs of apoptosis in CC. When these oocytes were allowed to mature in vitro, lysis extended all over the oocyte and $\mathrm{CC}$. When vitrification and warming of the oocytes took place after meiotic arrest and maturation lysis accounted for $50 \%$ of $\mathrm{CC}$, together with reduction in numbers of GJ, degeneration of mitochondria in both, $\mathrm{CC}$ and the oocyte, and absence of GC. These morphological alterations can be responsible for lack of development after IVF and IVC in these oocytes.

Although the cytoplasmic alterations observed in this work due to the meiotic arrest have been described elsewhere [17,18], the effects of cryopreservation in meiotically arrested oocytes are unknown. Our results show that combination of meiotic arrest and vitrification under our conditions is responsible for serious damages at the cellular level, making the oocytes unable to undergo IVF and subsequent embryonic development. Although our vitrification procedure yields low blastocysts rates, we suggest the matured oocyte as an appropriate stage to progress in research in oocyte vitrification. Our work contributes to identify factors involved in oocyte degeneration after cryopreservation as cytoplasmic organelle degeneration, lack of communication between the cumulus cells and the oocyte or alteration in the migration patterns of cortical granules. Improvement of cryopreservation procedures must focus on minimizing chilling injuries and finding less toxic cryoprotectants, as well as probably a specialized culture system to cryopreserved oocytes.

\section{Acknowledgements}

Dr. S. Ikeda and A. González for their help with electron microscopy. Robert Wellington for English reviewing. Supported by MCYT-FEDER; project AGL-2001-0379. 


\section{References}

[1] Woods EJ, Benson JD, Agca Y, Critser JK. Fundamental cryobiology of reproductive cells and tissues. Cryobiology 2004;48:146-56.

[2] Edwards RG. Maturation in vitro of mouse, sheep, cow, pig, rhesus monkey and human ovarian oocytes. Nature 1965;208:349-51.

[3] Kubelka M, Motlik J, Fulka Jr J, Prochazka R, Rimkevikova Z, Fulka J. Time sequence of germinal vesicle breakdown in pig oocytes after cycloheximide and $p$-aminobenzamidine block. Gam Res 1988; 19:423-31.

[4] Mermillod P, Tomanek M, Marchal R, Meijer L. High developmental competence of cattle oocytes maintained at the germinal vesicle stage for $24 \mathrm{~h}$ in culture by specific inhibition of MPF kinase activity. Mol Reprod Dev 2000;55:89-95.

[5] Vajta G, Holm P, Kuwayama M, Booth PJ, Jacobsen H, Greve T, et al. Open pulled straw (OPS) vitrification: a new way to reduce cryoinjuries of bovine ova and embryos. Mol Reprod Dev 1998;51:53-8.

[6] Vajta G. Oocyte and embryo vitrification. Reprod Dom Anim 1999;6(Suppl.):45-8.

[7] Vajta G, Lewis IM, Kuwayama M, Greve T, Callesen H. Sterile application of the open pulled straw (OPS) vitrification method. Cryo-letters 1998;19:392-8.

[8] Vajta G. Vitrification of the oocytes and embryos of domestic animals. Anim Reprod Sci 2000;60/61:357-64.

[9] Vieira AD, Mezzalira A, Barbieri DP, Lehmkuhl RC, Rubin MIB, Vajta G. Calves born after open pulled straw vitrification of immature bovine oocytes. Cryobiology 2002;45:91-4.

[10] Men H, Monson RL, Parrish JJ, Rutledge JJ. Degeneration of cryopreserved bovine oocytes via apoptosis during subsequent culture. Cryobiology 2003;47:73-81.

[11] Men H, Monson RL, Parrish JJ, Rutledge JJ. Detection of DNA damage in bovine metaphase II oocytes resulting from cryopreservation. Mol Reprod Dev 2003;64:245-50.

[12] Rodríguez KF, Farin CE. Developmental capacity of bovine cumulus oocyte complexes after transcriptional inhibition of germinal vesicle breakdown. Theriogenology 2004;61:1499-511.

[13] Schroeder AC, Champlin AK, Mobraaten LE, Eppig JJ. Developmental capacity of mouse oocytes cryopreserved before and after maturation in vitro. J Reprod Fertil 1990;89:43-50.

[14] Blondin P, Coenen K, Guibault L, Sirard M. In vitro competence of bovine embryos: developmental competence is acquired before maturation. Theriogenology 1997;47:1061-75.

[15] Hochi S, Ito K, Hirabayashi M, Ueda M, Kimura K, Hanada A. Effect of nuclear stages during IVM on the survival of vitrified-warmed bovine oocytes. Theriogenology 1998;49:787-96.

[16] Men H, Monson RL, Rutledge JJ. Effect of meiotic stages and maturation protocols on bovine oocyte's resistance to cryopreservation. Theriogenology 2002;57:1095-103.

[17] Faerge I, Mayes P, Hyttel P, Sirard MA. Nuclear ultrastructure in bovine oocytes after inhibition of meiosis by chemical and biological inhibitors. Mol Reprod Dev 2001;59:459-67.

[18] Lonergan P, Faerge I, Hyttel PD, Boland M, Fair T. Ultrastructural modifications in bovine oocytes maintained in meiotic arrest in vitro using roscovitine or butyrolactone. Mol Reprod Dev 2003;64:369-78.

[19] Duque P, Díez C, Royo LJ, Lorenzo PL, Carneiro G, Hidalgo CO, et al. Enhancement of developmental capacity of meiotically inhibited bovine oocytes by retinoic acid. Hum Reprod 2002;17:2706-14.

[20] Hidalgo C, Díez C, Duque P, Facal N, Prendes JM, Fernández I, et al. Improved cumulus-oocyte complex yields from heifers treated with retinol. Theriogenology 2002;57:672 (abstract).

[21] Hidalgo CO, Díez C, Duque P, Facal N, Gómez E. Pregnancies and improved early embryonic development in bovine oocytes matured in vitro with 9-cis-retinoic acid. Reproduction 2003;125:409-16.

[22] Gómez E, Rodríguez A, Goyache F, Díez C, Royo LJ, Moreira PN, et al. Retinoid-dependent mRNA expression and poly-(A) contents in bovine oocytes meiotically arrested and/or matured in vitro. Mol Reprod Dev 2004;69(1):101-8.

[23] Parrish JJ, Susko-Parrish JL, Leibifried-Ruthledge ML, Critser ES, Eyestone WH, First NL. Bovine in vitro fertilization with frozen-thawed semen. Theriogenology 1986;25:591-600.

[24] Holm P, Booth PJ, Schmidt MH, Greve T, Callesen H. High bovine blastocyst development in a static in vitro production system using SOFaa medium supplemented with sodium citrate and myo-inositol with or without serum-proteins. Theriogenology 1999;52:683-700.

[25] SAS Version 8.2, 1999. SAS Institute Inc., Cary, Inc. 
[26] Shaw JM, Oranratnachai A, Trounson AO. Fundamental cryobiology of mammalian oocytes and ovarian tissue. Theriogenology 2000;53:59-72.

[27] Zeron Y, Pearl M, Borochov A, Arav A. Kinetic and temporal factors influence chilling injury to germinal vesicle and mature bovine oocytes. Cryobiology 1999;38:35-42.

[28] Wu B, Tong J, Leibo SP. Effects of cooling germinal vesicle-stage bovine oocytes on meiotic spindle formation following in vitro fertilization. Mol Reprod Dev 1999;54:388-95.

[29] Vicent C, Johnson MH. Cooling, cryoprotectants, and the cytoskeleton of the mammalian oocytes. Oxford Rev Reprod Biol 1992;14:73-100.

[30] Van der Elst J, Nerinckx S, Van Steirteghem A. Association of ultrarapid freezing of mouse oocytes with increased polyploid at the pronucleate stage, reduced cell numbers in blastocysts, and impaired fetal development. J Reprod Fertil 1993;99:25-32.

[31] Aman RR, Parks JE. Effects of cooling and rewarming on the meiotic spindle and chromosomes of in vitro matured bovine oocytes. Biol Reprod 1994;50:103-10.

[32] Arav A, Shehu D, Mattioli M. Osmotic and cytotoxic study of vitrification of immature bovine oocytes. J Reprod Fertil 1993;99:353-8.

[33] Arav A, Zeron SB, Leslie SB, Behboodi E, Anderson GB, Crowe JH. Phase transition temperature and chilling sensitivity of bovine oocytes. Cryobiology 1996;33:589-99.

[34] Hansel W. The potential for improving the growth and development of cultured farm animal oocytes. Anim Reprod Sci 2003;79:191-201.

[35] Asada M, Ishibashi S, Ikumi S, Fukui Y. Effect of polyvinyl alcohol (PVA) concentration during vitrification of in vitro matured bovine oocytes. Theriogenology 2002;58:1199-208.

[36] Fuku E, Liu J, Downey BR. In vitro viability and ultrastructural changes in bovine oocytes treated with a vitrification solution. Mol Reprod Dev 1995;40:177-85.

[37] Hashimoto S, Minami N, Takakura R, Imai H. Bovine immature oocytes acquire developmental competence during meiotic arrest in vitro. Biol Reprod 2002;66:1696-701.

[38] Alworth AE, Albertini DF. Meiotic maturation in cultured bovine oocytes is accompanied by remodeling of the cumulus cell cytoskeleton. Dev Biol 1993;158:101-12.

[39] Hunter AG, Moor RM. Stage-dependent effects of inhibiting ribonucleic acids and protein synthesis on meiotic maturation of bovine oocytes in vitro. J Dairy Sci 1987;70:1646-52.

[40] Le Beux G, Richard FJ, Sirard MA. Effect of cycloheximide, 6-DMAP, roscovitine and butyrolactone I on resumption of meiosis in porcine oocytes. Theriogenology 2003;60:1049-58.

[41] Rzucidlo SJ, Gibbons J, Stice SL. Comparison by restriction fragment differential display RT-PCR gene expression pattern in bovine oocytes matured in the presence or absence of fetal calf serum. Mol Reprod Dev 2001;59:90-6.

[42] Sirard MA, Florman HM, Leibfried-Rutledge ML, Barner FL, Sims ML, First NL. Timing of nuclear progression and protein synthesis necessary for meiotic maturation of bovine oocytes. Biol Reprod 1989;40:1257-63.

[43] Rall WF. Factors affecting the survival of mouse embryos cryopreserved by vitrification. Cryobiology 1987;24:387-402.

[44] Sathananthan AH, Trounson A, Freeman L, Brady T. The effects of cooling human oocytes. Hum Reprod 1988;3:968-77.

[45] Fagbohun CF, Downs SM. Metabolic coupling and ligand stimulated meiotic maturation in the mouse oocyte cumulus cell complex. Biol Reprod 1991;45:851-9.

[46] Rodriguez KF, Farin CE. Gene transcription and regulation of oocyte maturation. Reprod Fertil Dev 2004;16:55-67.

[47] Ruppert-Lingham CJ, Paynter SJ, Godfrey J, Fuller BJ, Shaw RW. Developmental potential of murine germinal vesicle stage cumulus-oocyte complexes following exposure to dimethylsulphoxide or cryopreservation: loss of membrane integrity of cumulus cells after thawing. Hum Reprod 2003;18(2):392-8.

[48] Hyttel P, Greve T, Callesen H. Ultrastructural aspects of oocyte maturation and fertilization in cattle. J Reprod Fertil Suppl 1989;38:35-47.

[49] Hurtt AE, Landim-Alvarenga F, Seidel GE, Squires EI. Vitrification of immature and mature equine and bovine oocytes in an ethylene glycol, ficoll and sucrose solution using open pulled straws. Theriogenology 2000;54:119-28. 
[50] Carroll J, Depypere H, Matthews C. Freeze-thaw induced changes in the zona pellucida explains decreased rates of fertilization in frozen-thawed mouse oocyte. J Reprod Fertil 1990;90:547-53.

[51] Fuku E, Xia L, Downey BR. Ultrastructural changes in bovine oocytes cryopreserved by vitrification. Cryobiology 1995;32:139-56.

[52] Saunders K, Parks JE. Effects of cryopreservation procedures on the cytology and fertilization rate of in vitro-matured bovine oocytes. Biol Reprod 1999;61:178-87.

[53] Hyttel P, Vajta G, Callesen H. Vitrification of bovine oocytes with open pulled straw method: ultrastructural consequences. Mol Reprod Dev 2000;56:80-8.

[54] Sathananthan AH, Trounson A, Freeman L. Morphology and fertilizability of frozen human oocytes. Gam Res 1987;16:343-54.

[55] Azambuja RM, Kraemer DC, Westhusin ME. Effect of low temperatures on in-vitro matured bovine oocytes. Theriogenology 1998;49:1155-64. 